\title{
Adaptive laboratory evolution of Escherichia coli K-12 MG1655 for growth at high hydrostatic pressure
}

\author{
Angeliki Marietou ${ }^{\dagger}$, Alice T. T. Nguyen ${ }^{\dagger}$, Eric E. Allen and Douglas H. Bartlett* \\ Marine Biology Research Division, Center for Marine Biotechnology and Biomedicine, Scripps Institution of Oceanography, University of California, San Diego, \\ La Jolla, CA, USA
}

\section{Edited by:}

Mark Alexander Lever, Swiss

Federal Institute of Technology in

Zürich, Switzerland

Reviewed by:

Aude Picard, Harvard University,

USA

Christian Tamburini, Mediterranean

Institute of Oceanography, France

*Correspondence:

Douglas H. Bartlett, Marine Biology

Research Division, Center for

Marine Biotechnology and

Biomedicine, Scripps Institution of

Oceanography, University of

California, San Diego, 9500 Gilman

Drive, La Jolla, CA 92093-0202, USA

e-mail:dbartlett@ucsd.edu

${ }^{\dagger}$ These authors have contributed

equally to this work.
Much of microbial life on Earth grows and reproduces under the elevated hydrostatic pressure conditions that exist in deep-ocean and deep-subsurface environments. In this study adaptive laboratory evolution (ALE) experiments were conducted to investigate the possible modification of the piezosensitive Escherichia coli for improved growth at high pressure. After approximately 500 generations of selection, a strain was isolated that acquired the ability to grow at pressure non-permissive for the parental strain. Remarkably, this strain displayed growth properties and changes in the proportion and regulation of unsaturated fatty acids that indicated the acquisition of multiple piezotolerant properties. These changes developed concomitantly with a change in the gene encoding the acyl carrier protein, which is required for fatty acid synthesis.

Keywords: adaptive laboratory evolution, Escherichia coli, high pressure, piezophile, acpP

\section{INTRODUCTION}

Elevated hydrostatic pressure promotes reduced system volumes and volume changes of activation in chemical equilibria and rates of reactions, respectively (Meersman and McMillan, 2014). Microorganisms growing preferentially at elevated hydrostatic pressures exist in large portions of Earth's biosphere including deep-sea and deep-subsurface locations (Meersman et al., 2013). Despite the fact that the growth attributes of these piezophiles appear to require relatively little evolutionary change (Prieur et al., 2009), increased hydrostatic pressure exerts pervasive effects on many aspects of cellular function and the adaptations required remain incompletely defined (Lauro et al., 2008). Arguably the best understood adaptation is the need for bacterial piezophiles to maintain a sufficient proportion of unsaturated fatty acids in their membranes as a means of tuning phase, viscosity, and/or ion permeability (Bartlett, 2002; Kawamoto et al., 2011).

Escherichia coli is the most studied piezosensitive microorganism with the ability to grow to pressures of up to $50 \mathrm{MPa}$ (Zobell and Cobet, 1963). It has been successfully used as a model organism to investigate the effects of increasing pressure on cell processes and structures. E. coli belongs to the class of Gammaproteobacteria which includes a large proportion of the characterized piezophiles, while as a foodborne pathogen has been subjected to high pressure pasteurization processes potentially promoting the emergence of piezoresistant strains (Vanlint et al., 2012). High pressure affects many cellular processes in E. coli, including replication, transcription, and translation. Previous studies have demonstrated DNA synthesis inhibition at $50 \mathrm{MPa}$ while RNA synthesis was abolished completely at $77 \mathrm{MPa}$
(Yayanos and Pollard, 1969; Welch et al., 1993). Interestingly, a moderate pressure of $30 \mathrm{MPa}$ was sufficient to suppress gene transcription (Sato et al., 1996). Protein synthesis was completely inhibited at $68 \mathrm{MPa}$; aminoacyl-tRNA binding, ribosome translocation, and ribosome stability have all been implicated as the basis of high pressure impacts on translation (Schwarz and Landau, 1972; Groß and Jaenicke, 1990; Alpas et al., 2003). Cell division was affected at pressures ranging from 20 to $50 \mathrm{MPa}$ resulting in elongation of the cells and a filamentous morphology since cell division is affected prior to cell growth and accumulation of biomass (Zobell and Cobet, 1963). Pressure of $10 \mathrm{MPa}$ and higher affect flagellation by disrupting filament polymerization and flagellum rotation (Meganathan and Marquis, 1973). Other structural changes under high pressure include a compact nucleoid structure (Welch et al., 1993).

High pressure growth of $E$. coli at 30 or $50 \mathrm{MPa}$ induces a cascade of stress responses with the concomitant regulation of a series of genes; such cascade networks include heat and cold stress responses (Welch et al., 1993; Welch and Bartlett, 1998; Aertsen et al., 2004a; Ishii et al., 2005). Interestingly, heat shock pre-treatment improved the pressure resistance of $E$. coli in subsequent high pressure treatment, suggesting that heat shock proteins might play a protective role (Aertsen et al., 2004a). Finally, sub-lethal pressure treatments $(100-500 \mathrm{MPa})$ increased expression of stress sigma factors and genes involved in spontaneous mutations and triggered the SOS and oxidative stress responses (Aertsen et al., 2004b, 2005; Malone et al., 2006). Recently, a genome wide screening approach confirmed the pleiotropic effects of pressure on E. coli identifying a series of genes required 
for growth at high pressure, including genes involved in DNA replication, cell division, cytoskeleton, and cell envelope physiology (Black et al., 2013).

In this report we investigate the feasibility of employing adaptive laboratory evolution (ALE) techniques to drive the phenotype of a model mesophile in the direction of piezophily. ALE is a powerful tool that relies on the Darwinian principles of mutation and selection (Pourmir and Johannes, 2012). In some cases the selections involve a single selective step (Vanlint et al., 2011), in others a few hundred to a few thousand generations (Lee et al., 2011), and in the extreme case of the long-term studies of Lenski and colleagues they may proceed for more than 50,000 generations (Barrick et al., 2009). Examples of ALE experiments selecting for more extremophilic characteristics in mesophiles include increased salt tolerance (Zhou et al., 2013), increased radiation resistance (Harris et al., 2009), the conversion of a mesophile into a facultative thermophile (Blaby et al., 2012) and the selection for survival to exposures of more than 2 gigapascals of pressure (Hauben et al., 1997). It should be noted that resistance to ultra-high pressure does not confer improved growth at elevated pressures (Hauben et al., 1997; Lauro et al., 2008). In this study, following 505 generations of selection we have isolated a strain with the ability to grow at $62 \mathrm{MPa}$ and alter membrane fatty acid composition in response to pressure. A mutation has been identified in a gene involved in lipid metabolism that could contribute in the improved piezotolerance of the newly isolated strain.

\section{MATERIALS AND METHODS GROWTH CONDITIONS}

E. coli K-12 MG1655 was grown in triplicate lineages (A, B, and C) under fermentative conditions at $37^{\circ} \mathrm{C}$ using Luria Bertani (LB) medium supplemented with glucose $(11 \mathrm{mM})$ and HEPES buffer ( $100 \mathrm{mM}, \mathrm{pH} 7.5$ ) in $5 \mathrm{ml}$ polyethylene transfer pipette bulbs kept within stainless steel pressure vessels (Figure 1A). Initial incubations were performed at 41 megapascal $(\mathrm{MPa})$ and the growth was measured after $48 \mathrm{~h}$ of incubation. The cultures were allowed to reach a minimum optical density (OD) at $600 \mathrm{~nm}$ of 0.45

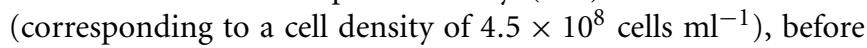
the cultures were diluted 1000-fold in fresh medium and reincubated at high pressure. Each triplicate subculture was assigned a new lineage number (i.e., L2A, 2B, 2C). The pressure was gradually increased in increments of $7 \mathrm{MPa}$ when cell yield exceeded $4.5 \times 10^{8}$ cells $\mathrm{ml}^{-1}$. Single clonal isolates from each culture were obtained by streaking LB agar plates and incubating for $48 \mathrm{~h}$ at $37^{\circ} \mathrm{C}$.

\section{MICROSCOPY AND IMAGE ANALYSIS}

Cells were fixed with $2 \%$ glutaraldehyde in $0.1 \mathrm{M}$ sodium cacodylate buffer ( $\mathrm{pH}$ 7.4) under in situ pressure conditions (Figure 1B) (Chastain and Yayanos, 1991). Two Sarstedt syringes were joined together using silicone adhesive creating a device with two chambers separated by a circular glass cover slip. The first chamber contained the culture while the second chamber contained the fixative solution and a stainless steel ball. The conjoined syringe was placed in a pressure vessel and incubated at $37^{\circ} \mathrm{C}$, at the desired pressure. To fix the cells the pressure vessel was shaken vigorously to cause the steel ball to break the glass cover slip and mix the fixative with the culture at in situ pressure conditions.

For epifluorescence microscopy the fixed cells were immobilized onto a $0.2 \mu \mathrm{m}$ polycarbonate membrane (EMD Millipore) and stained using $4^{\prime}, 6^{\prime}$-diamidino-2-phenylindole (DAPI) nucleic acid stain (Vector Laboratories, Inc). The stained samples were viewed at 1000 fold magnification on an Olympus BX51 fluorescence microscope (Olympus). TEM samples were post fixed with $1 \%$ osmium and $2 \%$ of uranyl acetate and embedded in Ducurpan at $60^{\circ} \mathrm{C}$ for $36 \mathrm{~h}$. Ultra-thin sections $(60 \mathrm{~nm})$ were cut with a diamond knife on Leica Ultracut UCT Microtome and post stained with uranyl acetate and lead. Images were captured on FEI Tecnai spirit at $80 \mathrm{KV}$.

\section{FATTY ACID ANALYSIS}

Fatty acid analysis was performed by MIDI Labs (Newark, DE) on frozen cell pellets harvested during the early logarithmic phase of growth. Saponification, methylation, extraction, and base wash were performed before the fatty acid methyl esters were analyzed on an Agilent/HP 6890 gas chromatograph. Using a pattern recognition software, Sherlock MIS, the fatty acid composition of each sample was compared to a stored database. The software was able to identify each component of the analyzed sample, producing a composition report including the relative amount (\%) of the named fatty acids.

\section{DNA PURIFICATION AND GENETIC ANALYSIS}

Cells growing at exponential phase were centrifuged at $14,000 \times$ $\mathrm{g}$ for $2 \mathrm{~min}$ and the cell pellets were used for DNA purification. The Wizard Genomic DNA purification kit (Promega) was used according to the manufacturer's instructions. The purified DNA was used as template for the amplification of the acp $P, f a b A, f a b B$, and $f a b F$ genes (see Table S1 for primer sequences and cycling parameters). Each PCR reaction contained $45 \mu$ l of Platinum PCR Supermix (Life Technologies), $2 \mu$ l of each primer $(10 \mu \mathrm{M})$ and $1 \mu \mathrm{l}$ of template DNA. The PCR products were purified using the QIAquick PCR Purification kit (Qiagen) and submitted for direct sequencing by Retrogen Inc. (San Diego, CA) using the respective primers in both directions.

\section{RESULTS}

\section{E. COLI GROWTH AT HIGH PRESSURE}

The ALE of E. coli for growth at high pressure was initiated by incubating triplicate cultures at $41 \mathrm{MPa}$. E. coli was grown at $41 \mathrm{MPa}$ for 103 generations prior to increasing the pressure to $48 \mathrm{MPa}$ for 247 generations, followed by incubation at $55 \mathrm{MPa}$ for 130 generations, and finally further increased to $62 \mathrm{MPa}$ for 25 generations (Figure 2). The total time required was 126 days and the total number of generations was 505. Improved high pressure growth of isolated strains was not evident until after selection for growth at the last pressure tested, $62 \mathrm{MPa}$, and this was only evident in cells derived from the lineage A population. Lineage $B$ and $\mathrm{C}$ did not respond as well as lineage $\mathrm{A}$ to the increasing pressure, failing to produce any cells capable of growth above $55 \mathrm{MPa}$. The last subculture collected was L62A, and from this population a single clonal isolate, designated strain AN62, was obtained from an LB agar plate. 
A

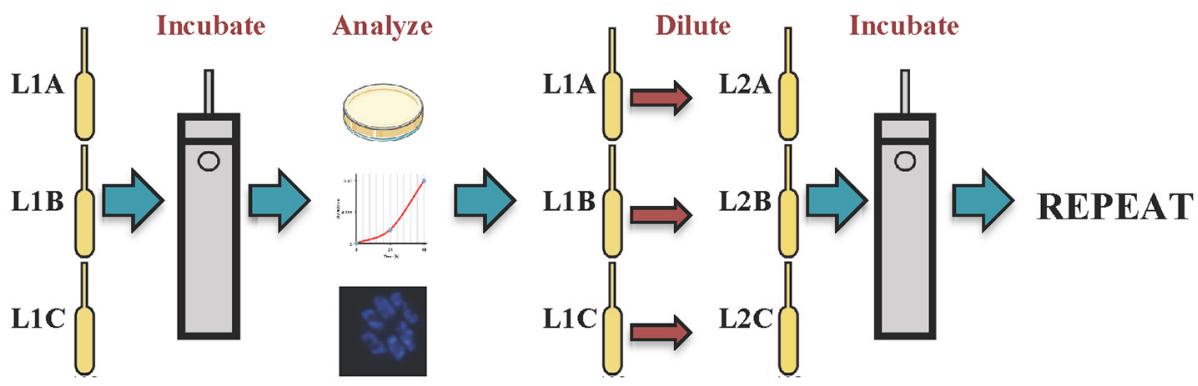

B

Creating a two-chamber device
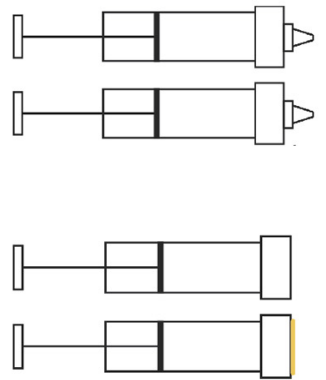

Two syringes, one cover slip
Fixative Culture

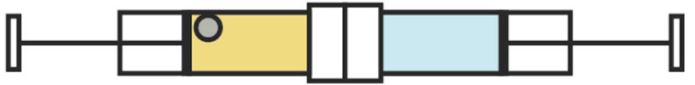

Place in pressure vessel and incubate
Shake to break glass and fix cells

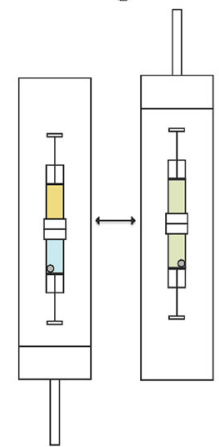

FIGURE 1 | Schematic diagram of the (A) adaptive laboratory evolution experimental procedure and (B) cell fixation under in situ pressure conditions.

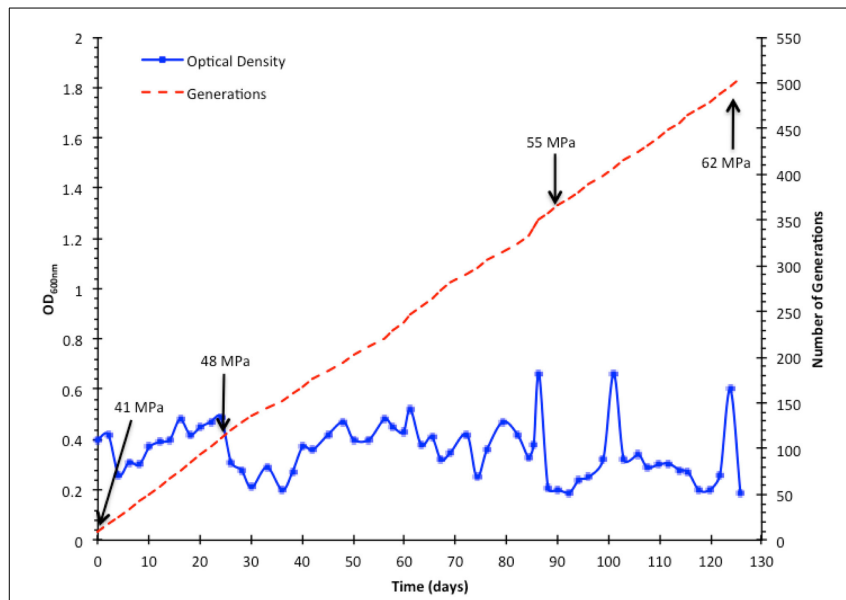

FIGURE 2 | Directed evolution of E. coli K-12 MG1655 to growth at high pressure. Cultures were grown under fermentative conditions to a minimum OD of 0.45 before they were diluted and incubated at increasing pressure at increments of $7 \mathrm{MPa}$. The OD values presented were recorded after $48 \mathrm{~h}$ of incubation for each subculture for lineage $\mathrm{A}$.

At atmospheric pressure the growth of clonal isolate AN62 was slower than the parental strain in liquid medium (Figure 3). The parental strain had a doubling time of 17 min while AN62 strain had a doubling time of $44 \mathrm{~min}$ when grown at $0.1 \mathrm{MPa}$. In contrast at $60 \mathrm{MPa}$ the parental strain was unable to grow, while AN62 grew after an extended lag phase of $\sim 20 \mathrm{~h}$ with a doubling time
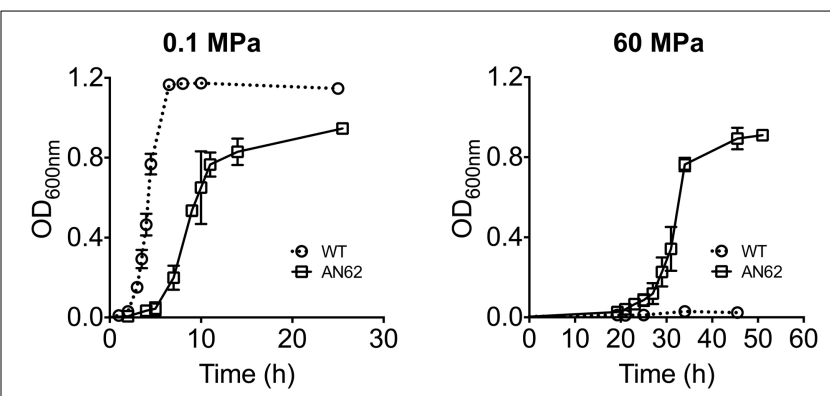

FIGURE 3 | Growth curves of E. coli K-12 MG1655 parental and pressure adapted AN62 strain at atmospheric (0.1 MPa) and high (60 MPa) pressure. Cultures were grown micro-aerobically in LB supplemented with glucose and HEPES buffer at $37^{\circ} \mathrm{C}$. WT, parental strain.

of $70 \mathrm{~min}$ (Figure 3 ). The same was true for colonial growth on agar plates; AN62 strain formed smaller colonies following a 48-h incubation compared to the parental strain (Figure 4).

\section{CELL MORPHOLOGY AT HIGH PRESSURE}

Epifluorescence microscopy and transmission electron microscopy (TEM) was used to determine whether any morphological changes accompanied the improved high pressure growth phenotype. The DAPI-stained parental strain (2 \pm $0.5 \mu \mathrm{m})$ and evolved strain AN62 $(2 \pm 0.4 \mu \mathrm{m})$ exhibited the typical rod shaped morphology of $E$. coli at atmospheric pressure (Figure 5). At $60 \mathrm{MPa}$ the few parental strain cells that were 
present maintained a rod shaped morphology, while AN62 cells primarily existed as long filaments with an average size of 6.6 $\pm 2 \mu \mathrm{m}$ (Figure 5). The parental strain cells appeared longer at $60 \mathrm{MPa}(2.5 \pm 1 \mu \mathrm{m}, p=0.037)$ compared to atmospheric pressure.

TEM confirmed the overall morphology indicated by the epifluorescence observations. Interestingly AN62 cells appeared darker at atmospheric pressure compared to the parental strain, suggesting the presence of a dense intracellular matrix (Figure 5). At $60 \mathrm{MPa}$ the majority of the AN62 cells appeared as long filaments $(7.2 \pm 2 \mu \mathrm{m})$. Growth at high pressure caused a change in the distribution of the nucleoid in the parental strain as it appeared condensed in the mid-cell region, while the internal structure of AN62 at high pressure resembled that of the parental strain at atmospheric pressure.

\section{MEMBRANE FATTY ACID COMPOSITION}

Because a hallmark feature of all piezophilic bacteria is a high ratio of unsaturated to saturated membrane fatty acids, the

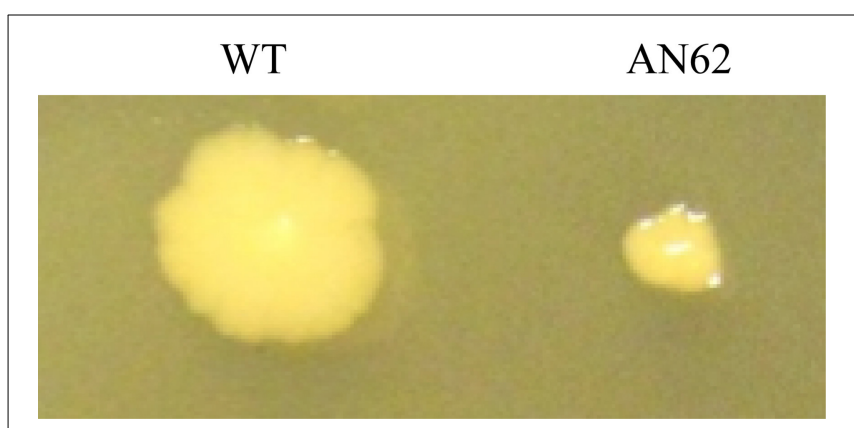

FIGURE 4 | Colony morphology of E. coli parental and AN62 strain. Cells were plated on LB plates and incubated for $48 \mathrm{~h}$ at $37^{\circ} \mathrm{C}$ at $0.1 \mathrm{MPa}$. WT, parental strain. fatty acid profiles of the parental and evolved strain were also compared. Under atmospheric pressure growth conditions the ratio of unsaturated to saturated fatty acids was similar for both the parental strain and AN62, although the former produced more palmitoleic acid $(16: 1 \omega 7 \mathrm{c})$ and the latter more cis-vaccenic acid $(18: 1 \omega 7 \mathrm{c})$. Remarkably, at $60 \mathrm{MPa}$ evolved strain AN62 increased its production of cis-vaccenic acid by about $50 \%$, up to more than $30 \%$ of the total fatty acid abundance, largely at the expense of the saturated fatty acid palmitic acid (16:0) (Table 1). There was insufficient biomass production at $60 \mathrm{MPa}$ for the parental strain membrane fatty acid analysis.

\section{GENETIC ANALYSIS}

Based on the altered unsaturated fatty acid species abundances produced in AN62 selected genes involved in fatty acid biosynthesis were sequenced. These genes included $a c p P$, encoding acyl carrier protein ACP, $f a b A$, encoding beta-hydroxydecanoyl thioester dehydrase, $f a b B$, encoding beta-ketoacyl-ACP synthase I (KAS I), and $f a b F$, encoding beta-ketoacyl-ACP synthase II (KAS II). Only one of these genes was discovered to possess a sequence difference with its homolog in the parental strain. The AN62 acpP gene contains a transversion mutation ( $\mathrm{T}$ to $\mathrm{G}$ ) at nucleotide position 131 resulting in a valine to glycine (V43G) amino acid change (Figure 6). The evolutionary history of this mutation was followed by assessing its presence or absence in strains derived from past lineages. Based on these analyses it was found that this mutation first appeared in lineage 60A, the same lineage found to possess the first cells adapted for improved high pressure growth (data not shown).

\section{DISCUSSION}

In this study, we used ALE to isolate a novel E. coli strain with the ability to grow at pressures that impede parental strain from growing. No E. coli strain has ever been documented to

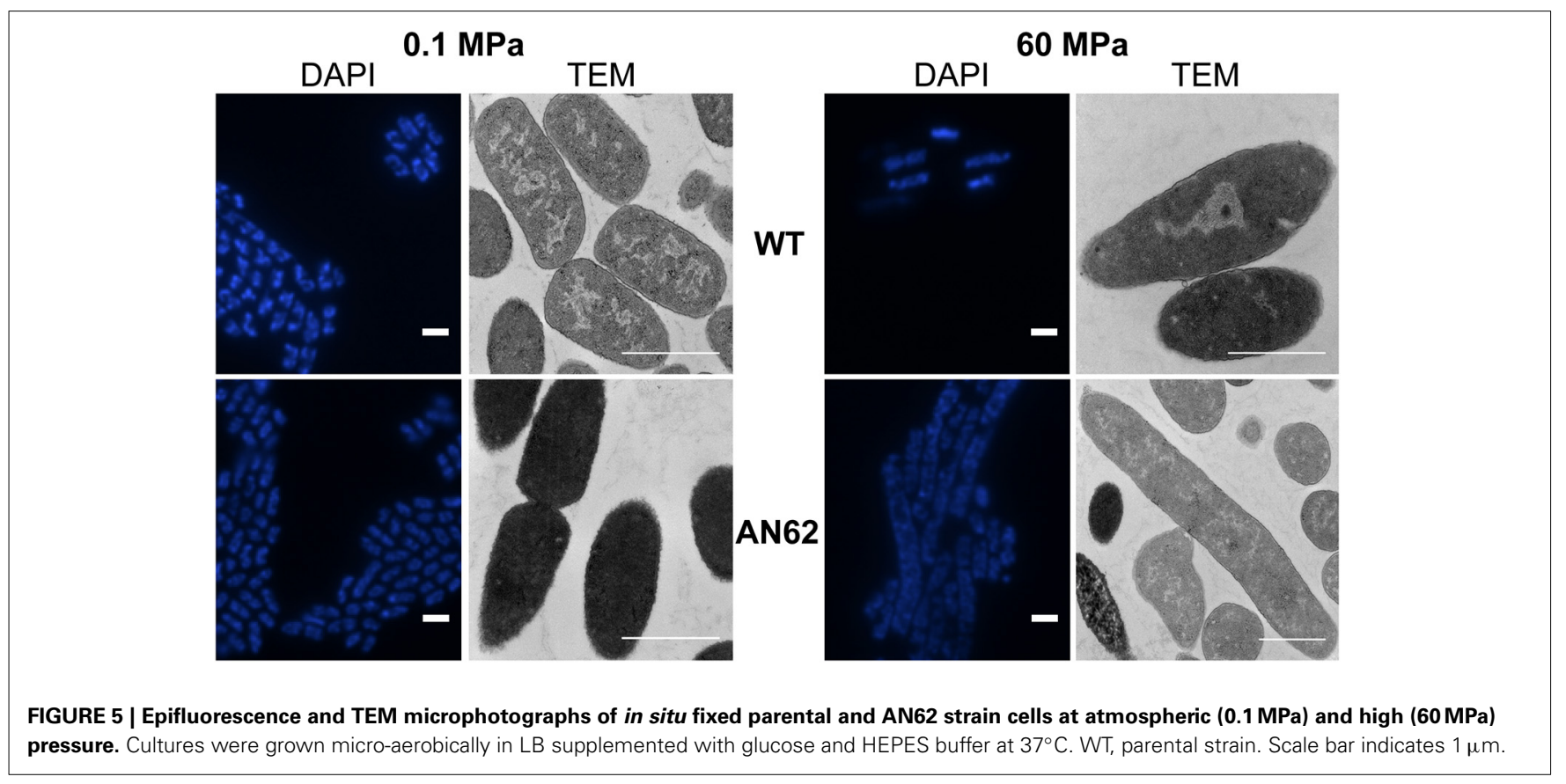


Table 1 | Fatty acid composition of E. coli K-12 MG1655 parental and AN62 strain at atmospheric $(0.1 \mathrm{MPa})$ and high $(60 \mathrm{MPa})$ pressure.

\begin{tabular}{|c|c|c|c|}
\hline \multirow[t]{3}{*}{ Fatty Acid } & WT & AN62 & AN62 \\
\hline & $0.1 \mathrm{MPa}$ & $0.1 \mathrm{MPa}$ & $60 \mathrm{MPa}$ \\
\hline & \multicolumn{3}{|c|}{$\%$ of total composition } \\
\hline $11: 030 \mathrm{H}$ & 0.04 & - & - \\
\hline $12: 0$ & 6.11 & 4.60 & 3.99 \\
\hline $12: 03 \mathrm{OH}$ & 0.07 & 0.06 & 0.08 \\
\hline $13: 0$ & 0.09 & 0.10 & - \\
\hline $14: 0$ & 9.37 & 6.14 & 5.54 \\
\hline $14: 03 \mathrm{OH}$ & 10.76 & 8.86 & 8.13 \\
\hline $15: 0$ & 0.19 & 0.13 & 0.10 \\
\hline $16: 0$ & 27.72 & 34.06 & 22.73 \\
\hline $16: 03 \mathrm{OH}$ & 0.08 & 0.07 & 0.09 \\
\hline $16: 1 \omega 5 c$ & 0.33 & 0.31 & 0.84 \\
\hline $16: 1 \omega 7 c$ & 31.66 & 20.46 & 20.72 \\
\hline $17: 0$ & 0.04 & 0.05 & 0.06 \\
\hline 17:0 cyclo & 2.22 & 2.93 & 3.59 \\
\hline $18: 0$ & 0.14 & 0.33 & 0.36 \\
\hline $18: 1 \omega 5 c$ & - & 0.11 & 0.25 \\
\hline $18: 1 \omega 7 c$ & 9.50 & 20.02 & 31.15 \\
\hline $18: 2 \omega 6,9 c$ & 0.04 & 0.06 & - \\
\hline $19: 0$ iso & 0.03 & - & - \\
\hline 19:0 cyclo $\omega 8 \mathrm{c}$ & 0.05 & 0.21 & 1.06 \\
\hline Unknown & 1.48 & 1.48 & 1.25 \\
\hline Sum (\%) & 99.99 & 99.98 & 99.99 \\
\hline UFA/SFA (\%) & 94.97 & 90.24 & 161.32 \\
\hline
\end{tabular}

Cultures were grown micro-aerobically in LB supplemented with glucose and HEPES buffer at $37^{\circ} \mathrm{C}$. Cells were harvested at the early exponential growth phase. WT, parental strain; UFA, unsaturated fatty acids; SFA, saturated fatty acids.

\begin{tabular}{|c|c|}
\hline & Helix II \\
\hline Ec WT & D S I D T V E L V M A L E E E F \\
\hline EC AN & D S L D T V E L G M A L E E E F \\
\hline Phpro & D S L D T V E L V M A L E E E F \\
\hline Shvio & D S L D T V E L V M A L E E E F \\
\hline Dhydr & D S L D I T E L I M A M E E E F \\
\hline Ddes 1 & D S I D I T E L I M A M E E E F \\
\hline Mpiez & D S L E L V D L T M A F E S E L \\
\hline \multicolumn{2}{|c|}{$\begin{array}{l}\text { FIGURE } 6 \text { | Multiple sequence alignment of helix II region of various } \\
\text { ACP. Identical residues are shaded gray, while red is used to highlight the } \\
\text { glycine in AN62 strain. Ec WT, E. coli parental strain; EC AN, E. coli AN62 } \\
\text { strain; Phpro, Photobacterium profundum SS9; Shvio, Shewanella violacea } \\
\text { DSS12; Dhydr, Desulfovibrio hydrothermalis AM13; Ddesl, Desulfovibrio } \\
\text { desulfuricans 27774; Mpiez, Marinitoga piezophila KA3. }\end{array}$} \\
\hline
\end{tabular}

grow at pressures exceeding $50 \mathrm{MPa}$ (Ishii et al., 2004). Although AN62 did not exhibit piezophilic growth, which would necessitate improved growth at high pressure compared to atmospheric pressure, its growth characteristics were altered at both ends of the pressure spectrum in a direction toward piezophily. This is the first time any microorganism has had its growth phenotype changed at both low and high pressure, although improved growth at high pressure has been noted in two other studies (Marquis and Bender, 1980; Abe and Horikoshi, 2000).

AN62 strain grew at $60 \mathrm{MPa}$ following an extended lag phase with a doubling time of 70 min (Figure 3). The extended lag phase observed for AN62 at $60 \mathrm{MPa}$ could be attributed to the physiological and molecular changes that the cells have to adjust before exponential growth can proceed at high pressure. Thus, even though AN62 strain has evolved to grow at $60 \mathrm{MPa}$ the changes required to switch from growth at atmospheric pressure to growth at high pressure suggest that the cells required a substantial amount of "fine-tuning," perhaps reflecting changes in transcription, translation, and/or the activity of key enzymes. Fatty acid biosynthesis is among the processes that are upregulated during lag phase (Rolfe et al., 2012) and the response of the fatty acid machinery to changes in pressure could have contributed to the observed extended lag phase. Finally, the relatively slow growth rate of AN62 under all pressure conditions indicates that this mutant did not evolve improved growth efficiency but rather improved high pressure growth capacity. The basis of its growth rate reduction, is unknown, but ATP supply and demand is strongly influenced by pressure in piezosensitive bacteria (Marquis, 1982). The significantly slower growth rate of AN62 at $60 \mathrm{MPa}$ could also reflect the constraints imposed on a larger cell volume due to inhibition of cell division at high pressure (Klumpp et al., 2009).

At $60 \mathrm{MPa}$, AN62 exhibited filamentous morphology in contrast to the parental strain which exhibited only a slightly elongated cell shape. It has previously been reported that E. coli assumes a typical filamentous morphology at the non-permissive pressure of $40 \mathrm{MPa}$ (Ishii et al., 2004). Filamentation is a welldocumented response of mesophilic bacteria to elevated pressures sufficiently high to inhibit cell division, but not so great as to prevent biomass accumulation (Jannasch, 1987; Yayanos and DeLong, 1987; Kawarai et al., 2004). The basis of this effect may stem from direct effects on the tubulin-like cell division protein FtsZ (Ishii et al., 2004) or through the induction of a DNA damage stress response (Aertsen and Michiels, 2005). When pressures high enough to prevent growth were applied to AN62 (75 MPa), no change in morphology occurred. Thus, along with its growth properties the filamentation response of AN62 was shifted to higher pressures.

Growth at suboptimal pressures also causes substantial changes to the morphology of known piezophiles. Marinitoga piezophila KA3 cells are short rods $(1-1.5 \mu \mathrm{m})$ when grown at the optimal pressure of $40 \mathrm{MPa}$ (Alain et al., 2002). However, when the cells are grown at $10 \mathrm{MPa}$ or atmospheric pressure they appear elongated (Alain et al., 2002). Similarly, Profundimonas piezophila cells are rods $(4-5 \mu \mathrm{m})$ when grown at $60 \mathrm{MPa}$ (pressure optimum $50 \mathrm{MPa}$ ) and their morphology changes to $0.8-1.0 \mu \mathrm{m}$ cocci when grown at pressures lower than $20 \mathrm{MPa}$ (Cao et al., 2014). Interestingly, following nine transfers at atmospheric pressure M. piezophila KA3 exhibited the short rod morphotype. These observations highlight the effect of pressure on cell morphology and indicate that adaptation to higher or lower pressures is accompanied by cell size changes. 
Strain AN62 produced on overall more cis-vaccenic acid, while its relative amount increased further at $60 \mathrm{MPa}$. These results indicate that not only had the mutant strain acquired the ability to produce more unsaturated fatty acids, but also it had gained the ability to regulate their abundance in response to the pressure applied. Both of these phenotypes are shared with piezophilic bacteria (Allen and Bartlett, 2000). The molecular mechanisms underlying such a response to increasing pressure remains largely unexplored.

Previous studies highlighted the importance of fatty acid synthesis genes in temperature and pressure response modulation (Garwin and Cronan, 1980; Garwin et al., 1980; Allen and Bartlett, 2000). ACP is a conserved protein that interacts with several other proteins including some with known role in lipid metabolism (Worsham et al., 2003). ACP carries fatty acid synthesis intermediates as thiosters (Rock and Jackowski, 2002). The V43G mutation is located in the helix II region; a site of interaction with several proteins involved in fatty acid synthesis (Jackowski and Rock, 1987). There is a high degree of identity among type II ACP homologs, including position V43 (Jackowski and Rock, 1987). This is also true for most but not all piezophiles. For example, the well-studied piezophiles Photobacterium profundum and Shewanella violacea possess V43, whereas the piezophiles Desulfovibrio hydrothermalis and $M$. piezophila have isoleucine and threonine at position V43, respectively. The presence of V43 in well studied piezophiles is indicating that modification of this residue is not a universal feature of high pressure adaptation.

Previous studies in E. coli have established that a V43I substitution affects the ACP equilibrium to a more compact, tightlyfolded conformation by stabilizing the hydrophobic core of the protein and decreasing the molecular radius (Keating and Cronan, 1996; Roujeinikova et al., 2002). The V43I substitution is hypothesized to also increase the efficiency of unsaturated fatty acid synthesis (Roujeinikova et al., 2002).

We hypothesize that the mutation uncovered in acp $P$ is linked to KAS II activity, both because of the associated increased production of cis-vaccenic acid synthesis observed in AN62 (Garwin et al., 1980; Jackowski and Rock, 1987; Allen and Bartlett, 2000) and because of prior evidence linking ACP structure with KAS II activity (Jackowski and Rock, 1987). KAS II is responsible for increased cis-vaccenic acid production in response to lower growth temperature (Garwin et al., 1980). It catalyzes the elongation of palmitoleic (16:1) to cis-vaccenic acid (18:1). Interestingly, thermal regulation of cis-vaccenic acid synthesis is not controlled at the transcriptional or translation level but is depended on KAS II activity (Garwin and Cronan, 1980). KAS II mutants with impaired activity possessed ACP proteins with the V43I mutation suggesting that V43 residue has an important role in KAS II/ACP interaction with effects on fatty acid synthesis (Jackowski and Rock, 1987).

It is likely that the observed genetic change is necessary but insufficient for piezoadaptation. Additional studies will be needed to identify and confirm all mutations necessary and sufficient for the high pressure phenotypes of AN62. It will also be of interest to determine how much further ALE experiments can drive E. coli and other non-piezophiles along the gradient of piezophily. In the case of obligate piezophiles ALE experiments could be used to determine the adaptations required for the evolution of growth and survival at decreased pressures.

ALE could improve our understanding of the evolutionary steps required for the adaptation of life at extremes of pressure. The environmentally relevant exposure of piezosensitive surface microbes to increases in pressure could proceed by a variety of different mechanisms including in association with metazoans undergoing extensive vertical migrations, or in association with large carrion or smaller aggregates of particulate organic carbon. The vertical travel speeds of particle-associated microbes have been estimated to range from 10 to $150 \mathrm{~m} \mathrm{~d}^{-1}$ (McDonnell et al., 2010). At increasing depths travel speed increases by a factor of $10-60 \%$, while pressure increases by $1 \mathrm{MPa}$ every $100 \mathrm{~m}$ (Berelson, 2001). Sufficient growth could occur during these transits to enable the acquisition of the requisite number and types of mutations needed for selection of high pressure growth mutants of increased fitness.

Our results demonstrate that it is possible to drive the evolutionary trajectory of a piezosensitive bacterium along the pressure continuum toward piezophily, and to archive the evolutionary history of this process for the subsequent examination of the associated mutational events. ALE experiments performed in this way provide a new approach to characterize the genetic underpinnings enabling microbial life to flourish under the extreme physical constraint of high pressure (low volume change).

\section{ACKNOWLEDGMENT}

This work was supported by grants from the National Science Foundation (EF-0801793 and EF-0827051) and the Sloan Foundation Deep Carbon Observatory to Douglas H. Bartlett.

\section{SUPPLEMENTARY MATERIAL}

The Supplementary Material for this article can be found online at: http://www.frontiersin.org/journal/10.3389/fmicb. 2014.00749/abstract

\section{REFERENCES}

Abe, F., and Horikoshi, K. (2000). Tryptophan permease gene TAT2 confers highpressure growth in Saccharomyces cerevisiae. Mol. Cell. Biol. 20, 8093-8102. doi: 10.1128/MCB.20.21.8093-8102.2000

Aertsen, A., De Spiegeleer, P., Vanoirbeek, K., Lavilla, M., and Michiels, C. W. (2005). Induction of oxidative stress by high hydrostatic pressure in Escherichia coli. Appl. Environ. Microbiol. 71, 2226-2231. doi: 10.1128/AEM.71.5.22262231.2005

Aertsen, A., Houdt, R. V., Vanoirbeek, K., and Michiels, C. W. (2004b). An SOS response induced by high pressure in Escherichia coli. J. Bacteriol. 186, 6133-6141. doi: 10.1128/JB.186.18.6133-6141.2004

Aertsen, A., and Michiels, C. W. (2005). Mrr instigates the SOS response after high pressure stress in Escherichia coli. Mol. Microbiol. 58, 1381-1391. doi: 10.1111/j.1365-2958.2005.04903.x

Aertsen, A., Vanoirbeek, K., De Spiegeleer, P., Sermon, J., Hauben, K., Farewell, A., et al. (2004a). Heat shock protein-mediated resistance to high hydrostatic pressure in Escherichia coli. Appl. Environ. Microbiol. 70, 2660-2666. doi: 10.1128/AEM.70.5.2660-2666.2004

Alain, K., Marteinsson, V. T., Miroshnichenko, M. L., Bonch-Osmolovskaya, E. A., Prieur, D., and Birrien, J. L. (2002). Marinitoga piezophila sp. nov., a rod-shaped, thermo-piezophilic bacterium isolated under high hydrostatic pressure from a deep-sea hydrothermal vent. Int. J. Syst. Evol. Microbiol. 52, 1331-1339. doi: 10.1099/ijs.0.02068-0

Allen, E. E., and Bartlett, D. H. (2000). FabF is required for piezoregulation of cis-vaccenic acid levels and piezophilic growth of the deep-sea bacterium 
Photobacterium profundum strain SS9. J. Bacteriol. 182, 1264-1271. doi: 10.1128/JB.182.5.1264-1271.2000

Alpas, H., Lee, J., Bozoglu, F., and Kaletunc, G. (2003). Evaluation of high hydrostatic pressure sensitivity of Staphylococcus aureus and Escherichia coli 157:H7 by differential scanning calorimetry. Int. J. Food Microbiol. 87, 229-237. doi: 10.1016/S0168-1605(03)00066-7

Barrick, J. E., Yu, D. S., Yoon, S. H., Jeong, H., Oh, T. K., Schneider, D., et al. (2009). Genome evolution and adaptation in a long-term experiment with Escherichia coli. Nature 461, 1243-1247. doi: 10.1038/nature08480

Bartlett, D. H. (2002). Pressure effects on in vivo processes. Biochim. Biophys. Acta. 1595, 367-381. doi: 10.1016/S0167-4838(01)00357-0

Berelson, W. M. (2001). Particle settling rates increase with depth in the ocean. Deep Sea Res. Part II Top. Stud. Oceanogr. 49, 237-251. doi: 10.1016/S09670645(01)00102-3

Blaby, I. K., Lyons, B. J., Wroclawska-Hughes, E., Phillips, G. C., Pyle, T. P., Chamberlin, S. G., et al. (2012). Experimental evolution of a facultative thermophile from a mesophilic ancestor. Appl. Environ. Microbiol. 78, 144-155. doi: 10.1128/AEM.05773-11

Black, S. L., Dawson, A., Ward, F. B., and Allen, R. J. (2013). Genes required for growth at high hydrostatic pressure in Escherichia coli K-12 identified by genome-wide screening. PLoS ONE 8:e73995. doi: 10.1371/journal.pone.0073995

Cao, Y., Chastain, R. A., Eloe, E. A., Nogi, Y., Kato, C., and Bartlett, D. H. (2014). Novel psychropiezophilic Oceanospirillales species Profundimonas piezophila gen. nov., sp. nov., isolated from the deep-sea environment of the Puerto Rico Trench. Appl. Environ. Microbiol. 80, 54-60. doi: 10.1128/AEM.02288-13

Chastain, R. A., and Yayanos, A. A. (1991). Ultrastructural changes in an obligately barophilic marine bacterium after decompression. Appl. Environ. Microbiol. 57, 1489-1497.

Garwin, J. L., and Cronan, J. E. (1980). Thermal modulation of fatty acid synthesis in Escherichia coli does not involve de novo enzyme synthesis. J. Bacteriol. 141, 1457-1459.

Garwin, J. L., Klages, A. L., and Cronan, J. E. (1980). Beta-ketoacyl-acyl carrier protein synthase II of Escherichia coli. Evidence for function in the thermal regulation of fatty acid synthesis. J. Biol. Chem. 255, 3263-3265.

Groß, M., and Jaenicke, R. (1990). Pressure-induced dissociation of tight couple ribosomes. FEBS Lett. 267, 239-241. doi: 10.1016/0014-5793(90) 80934-B

Harris, D. R., Pollock, S. V., Wood, E. A., Goiffon, R. J., Klingele, A. J., Cabot, E. L., et al. (2009). Directed evolution of ionizing radiation resistance in Escherichia coli. J. Bacteriol. 191, 5240-5252. doi: 10.1128/JB.00502-09

Hauben, K. J., Bartlett, D. H., Soontjens, C. C., Cornelis, K., Wuytack, E. Y., and Michiels, C. W. (1997). Escherichia coli mutants resistant to inactivation by high hydrostatic pressure. Appl. Environ. Microbiol. 63, 945-950.

Ishii, A., Oshima, T., Sato, T., Nakasone, K., Mori, H., and Kato, C. (2005). Analysis of hydrostatic pressure effects on transcription in Escherichia coli by DNA microarray procedure. Extremophiles 9, 65-73. doi: 10.1007/s00792-00 4-0414-3

Ishii, A., Sato, T., Wachi, M., Nagai, K., and Kato, C. (2004). Effects of high hydrostatic pressure on bacterial cytoskeleton FtsZ polymers in vivo and in vitro. Microbiology 150, 1965-1972. doi: 10.1099/mic.0.26962-0

Jackowski, S., and Rock, C. O. (1987). Altered molecular form of acyl carrier protein associated with beta-ketoacyl-acyl carrier protein synthase II (fabF) mutants. J. Bacteriol. 169, 1469-1473.

Jannasch, H. W. (1987). "Effects of hydrostatic pressure on growth of marine bacteria," in Current Perspectives in High Pressure Biology, eds H. W. Jannasch, R. E. Marquis, and A. M. Zimmerman (Toronto, ON: Academic Press), 1-15.

Kawamoto, J., Sato, T., Nakasone, K., Kato, C., Mihara, H., Esaki, N., et al. (2011). Favourable effects of eicosapentaenoic acid on the late step of the cell division in a piezophilic bacterium, Shewanella violacea DSS12, at highhydrostatic pressures. Environ. Microbiol. 13, 2293-2298. doi: 10.1111/j.14622920.2011.02487.x

Kawarai, T., Wachi, M., Ogino, H., Furukawa, S., Suzuki, K., Ogihara, H., et al. (2004). SulA-independent filamentation of Escherichia coli during growth after release from high hydrostatic pressure treatment. Appl. Microbiol. Biotechnol. 64, 255-262. doi: 10.1007/s00253-003-1465-6

Keating, D. H., and Cronan, J. E. (1996). An isoleucine to valine substitution in Escherichia coli acyl carrier protein results in a functional protein of decreased molecular radius at elevated pH. J. Biol. Chem. 271, 15905-15910. doi: 10.1074/jbc.271.27.15905
Klumpp, S., Zhang, Z., and Hwa, T. (2009). Growth rate-dependent global effects on gene expression in bacteria. Cell 139, 1366-1375. doi: 10.1016/j.cell.2009.12.001

Lauro, F. M., Tran, K., Vezzi, A., Vitulo, N., Valle, G., and Bartlett, D. H. (2008). Large-scale transposon mutagenesis of Photobacterium profundum SS9 reveals new loci important for growth at low temperature and high pressure. J. Bacteriol. 190, 1699-1709. doi: 10.1128/JB.01176-07

Lee, D. H., Feist, A. M., Barrett, C. L., and Palsson, B. Ø. (2011). Cumulative number of cell divisions as a meaningful timescale for adaptive laboratory evolution of Escherichia coli. PLoS ONE 6:e26172. doi: 10.1371/journal.pone.0026172

Meganathan, R., and Marquis, R. E. (1973). Loss of bacterial motility under pressure. Nature 246, 525-527. doi: 10.1038/246525a0

Malone, A. S., Chung, Y. K., and Yousef, A. E. (2006). Genes of Escherichia coli $\mathrm{O} 157: \mathrm{H} 7$ that are involved in high-pressure resistance. Appl. Environ. Microbiol. 72, 2661-2671. doi: 10.1128/AEM.72.4.2661-2671.2006

Marquis, R. E. (1982). Microbial barobiology. Bioscience 32, 267-271. doi: $10.2307 / 1308533$

Marquis, R. E., and Bender, G. R. (1980). Isolation of a variant of Streptococcus faecalis with enhanced barotolerance. Can. J. Microbiol. 26, 371-376. doi: $10.1139 / \mathrm{m} 80-060$

McDonnell, Z., Andrew, M. P., and Buesseler, K. O. (2010). Variability in the average sinking velocity of marine particles. Limnol. Oceanogr. 55, 2085-2096. doi: 10.4319/lo.2010.55.5.2085

Meersman, F., Daniel, I., Bartlett, D. H., Winter, R., Hazael, R., and McMillain, P. F. (2013). High-pressure biochemistry and biophysics. Rev. Mineral. Geochem. 75, 607-648. doi: $10.2138 / \mathrm{rmg} .2013 .75 .19$

Meersman, F., and McMillan, P. F. (2014). High hydrostatic pressure: a probing tool and a necessary parameter in biophysical chemistry. Chem. Commun. 50, 766-775. doi: $10.1039 / \mathrm{c} 3 \mathrm{cc} 45844 \mathrm{j}$

Pourmir, A., and Johannes, T. W. (2012). Directed evolution: selection of the host organism. Comput. Struct. Biotechnol. J. 2:e201209012. doi: 10.5936/csbj.201209012

Prieur, D., Jebbar, M., Bartlett, D., Kato, C., and Oger, P. (2009). "Piezophilic prokaryotes," in Comparative High Pressure Biology, ed E. Sebert (Enfield, NH: Science Publishers), 285-322.

Rock, C. O., and Jackowski, S. (2002). Forty years of bacterial fatty acid synthesis. Biochem. Biophys. Res. Commun. 292, 1155-1166. doi: 10.1006/bbrc.2001.2022

Rolfe, M. D., Rice, C. J., Lucchini, S., Pin, C., Thompson, A., Cameron, A. D. S., et al. (2012). Lag phase is a distinct growth phase that prepares bacteria for exponential growth and involves transient metal accumulation. J. Bacteriol. 194, 686-701. doi: 10.1128/JB.06112-11

Roujeinikova, A., Baldock, C., Simon, W. J., Gilroy, J., Baker, P. J., Stuitje, A. R., et al. (2002). X-ray crystallographic studies on butyryl-ACP reveal flexibility of the structure around a putative acyl chain binding site. Structure 10, 825-835. doi: 10.1016/S0969-2126(02)00775-X

Sato, T., Nakamura, Y., Nakashima, K. K., Kato, C., and Horikoshi, K. (1996). High pressure represses expression of the malB operon in Escherichia coli. FEMS Microbiol. Lett. 135, 111-116. doi: 10.1111/j.1574-6968.1996.tb07974.x

Schwarz, J. R., and Landau, J. V. (1972). Hydrostatic pressure effects on Escherichia coli: site of inhibition of protein synthesis. J. Bacteriol. 109, 945-948.

Vanlint, D., Mitchell, R., Bailey, E., Meersman, F., McMillan, P. F., Michiels, C. W., et al. (2011). Rapid acquisition of gigapascal-high-pressure resistance by Escherichia coli. MBio 2, e00130-e00110. doi: 10.1128/mBio.00130-10

Vanlint, D., Rutten, N., Michiels, C. W., and Aertsen, A. (2012). Emergence and stability of high-pressure resistance in different food-borne pathogens. Appl. Environ. Microbiol. 78, 3234-3241. doi: 10.1128/AEM.00030-12

Welch, T. J., and Bartlett, D. H. (1998). Identification of a regulatory protein required for pressure-responsive gene expression in the deep-sea bacterium Photobacterium species strain SS9. Mol. Microbiol. 27, 977-985. doi: 10.1046/j.1365-2958.1998.00742.x

Welch, T. J., Farewell, A., Neidhardt, F. C., and Bartlett, D. H. (1993). Stress response of Escherichia coli to elevated hydrostatic pressure. J. Bacteriol. 175, 7170-7177.

Worsham, L. M. S., Earls, L., Jolly, C., Langston, K. G., Trent, M. S., and ErnstFonberg, M. L. (2003). Amino acid residues of Escherichia coli acyl carrier protein involved in heterologous protein interactions. Biochemistry 42, 167-176. doi: 10.1021/bi0261950

Yayanos, A. A., and DeLong, E. F. (1987). "Deep-sea bacterial fitness to environmental temperatures and pressures," in Current Perspectives in High Pressure Biology, eds H. W. Jannasch, R. E. Marquis, and A. M. Zimmerman (Toronto, ON: Academic Press), 17-32. 
Yayanos, A. A., and Pollard, E. C. (1969). A study of the effects of hydrostatic pressure on macromolecular synthesis in Escherichia coli. Biophys. J. 9, 1464-1482. doi: 10.1016/S0006-3495(69)86466-0

Zhou, A., Baidoo, E., He, Z., Mukhopadhyay, A., Baumohl, J. K., Benke, P., et al. (2013). Characterization of $\mathrm{NaCl}$ tolerance in Desulfovibrio vulgaris Hildenborough through experimental evolution. ISME J. 7, 1790-1802. doi: 10.1038/ismej.2013.60

Zobell, C. E., and Cobet, A. B. (1963). Filament formation by Escherichia coli at increased hydrostatic pressures. J. Bacteriol. 87, 710-719.

Conflict of Interest Statement: The authors declare that the research was conducted in the absence of any commercial or financial relationships that could be construed as a potential conflict of interest.
Received: 11 October 2014; accepted: 10 December 2014; published online: 07 January 2015.

Citation: Marietou A, Nguyen ATT, Allen EE and Bartlett DH (2015) Adaptive laboratory evolution of Escherichia coli K-12 MG1655 for growth at high hydrostatic pressure. Front. Microbiol. 5:749. doi: 10.3389/fmicb.2014.00749

This article was submitted to Extreme Microbiology, a section of the journal Frontiers in Microbiology.

Copyright (C) 2015 Marietou, Nguyen, Allen and Bartlett. This is an open-access article distributed under the terms of the Creative Commons Attribution License (CC BY).

The use, distribution or reproduction in other forums is permitted, provided the original author(s) or licensor are credited and that the original publication in this journal is cited, in accordance with accepted academic practice. No use, distribution or reproduction is permitted which does not comply with these terms. 